Revista Kinesis, Santa Maria v.35 n.3, 2017, Set - dez , p. 46 - 56 Centro de Educação Física e Desporto - UFSM

\title{
A ATUAÇÃO DO PROFESSOR DE EDUCAÇÃO FÍSICA COMO GESTOR ESCOLAR
}

\author{
THE PHYSICAL EDUCATION TEACHER'S AS A SCHOOL MANAGER
}

\section{LA ACTUACIÓN DEL PROFESOR DE EDUCACIÓN FÍSICA COMO GESTOR ESCOLAR}

\author{
Augusto Pedretti \\ pedrettiaugusto@gmail.com \\ Universidade Federal do Rio Grande do Sul \\ Luana Fraga da Silva Leite \\ luana_fragaog@hotmail.com \\ Universidade Federal de Juiz de Fora \\ Júlio Mello \\ juliobmello@hotmail.com \\ Universidade Federal do Rio Grande do Sul \\ Rafaela Pinheiro Lacerda \\ rafaela_cerda@hotmail.com \\ Universidade Federal de Juiz de Fora \\ Selva Maria Guimarães Barreto \\ selva.barreto@ufff.edu.br \\ Universidade Federal de Juiz de Fora
}

\begin{abstract}
RESUMO
O objetivo deste estudo foi descrever a importância da gestão escolar para o professor de Educação Física e o comportamento deste como gestor. Foram entrevistados 16 professores de Educação Física de ambos os sexos da cidade de Juiz de Fora. Trata-se de um estudo com método descritivo, abordagem qualitativa e técnica narrativa. As respostas foram descritas de maneira a preservar a identidade dos entrevistados, seguindo a ordem das perguntas feitas em cada bloco. Através disso pôde concluir-se que os professores entrevistados, apesar de se considerarem gestores, por muitas vezes não se sentem capazes de ser um gestor escolar. Palavras-Chave: Educação Escolar, Educação Física, Gestão Escolar.
\end{abstract}

\section{ABSTRACT}

The purpose of this study was to describe the importance of school management for the Physical Education teacher and his behavior as a manager. We interviewed 16 teachers of Physical Education of both sexes of the city of Juiz de Fora. It is a study with descriptive method, qualitative approach and narrative technique. The answers were described in such a way as to preserve the identity of the interviewees, following the order of the questions asked in each block. Through this it can be concluded that the teachers interviewed, although they consider themselves managers, often do not feel capable of being a school manager. Keywords: School Education, Physical Education, School Management.

\section{RESUMEN}

El objetivo del estudio fue describir la importancia de la gestión escolar para el maestro de educación física y lo comportamiento de esto administrador. Han entrevistados 16 maestros de Educación Física de ambos los sexos de la ciudad de Juiz de Fora. Esto se trata de un estudio con método descriptivo, abordaje cualitativo y técnica narrativa. Las respuestas han sido descritas de manera a preservar la identidad de los entrevistados, en seguida la orden de las cuestiones realizadas en cada bloco. Atreves de esto pode se concluir que los maestros entrevistados, a pesar de ser consideraren un gestor, por muchas veces non se sienten capases de ser un gestor de la escuela. Palabras Clave: Educación Física, Gestión Escolar 


\section{INTRODUÇÃO}

A Educação Física na escola é definida como a disciplina que trata da cultura corporal do movimento humano (GAYA, 2008), portanto, é rica em conteúdos. Apesar das constantes modificações sobre o seu papel, tem contribuído de forma efetiva na formação de cidadãos capazes de ingressar nas diversas práticas corporais e de se integrar à sociedade.

Entretanto, grande parte da sociedade e dos próprios professores de Educação Física desconhece o real valor e o papel desta disciplina na escola, desvalorizando-a e subestimando-a, fato que pode ser um importante fator para que os professores de Educação Física se afastem das decisões tomadas nas escolas (ILHA e KRUG, 2008). Todavia, ao longo do processo de construção de uma sociedade democrática, uma das grandes vitórias das escolas no campo político-educativo foi à conquista da liberdade de ação e de decisão em relação aos órgãos superiores da administração (KRAWCZYK, 1999), portanto, a falta de participação ou a própria inibição dela pode afetar inclusive o sistema de gestão escolar como um todo.

Tendo em vista o processo histórico de construção da nova perspectiva de gestão escolar (KRAWCZYK, 1999), em que a proposta de direção colegiada ganhou força, a formação da gestão escolar por representantes de todos os membros envolvidos no processo educativo é um direito e passa a ser também um dever de todos os professores (WARDE, 1992).

Neste contexto, apenas as vivências práticas na escola são insuficientes para construir mudanças e participar de forma decisiva no processo de formação e gestão escolar. Cabe ao professor a busca por conhecimentos mais abrangentes, ideias e métodos capazes de atingir seus objetivos. Tal conjuntura torna os conhecimentos de gestão uma excelente alternativa, pois, nesta área, se estima uma constante busca por informações e habilidades empreendedoras (BASTOS e MAZZEI, 2012).

A gestão escolar, como o próprio nome diz, refere-se à esfera de abrangência dos estabelecimentos de ensino. A LDB de 1996 foi à primeira das leis de educação a dispensar atenção particular à gestão escolar, atribuindo um significativo número de incumbências às unidades de ensino. Esta perspectiva assinala um momento em que a escola passa a configurar-se como um novo foco da política educacional (VIEIRA; ALBUQUERQUE, op. cit.). As incumbências às unidades de ensino de acordo com a LDB de 1996 são de:

\footnotetext{
“elaborar e executar sua proposta pedagógica; administrar seu pessoal e seus recursos materiais e financeiros; assegurar o cumprimento dos dias letivos e horas-aula estabelecidas; velar pelo cumprimento do plano de trabalho de cada docente; prover meios para a recuperação de alunos de menor rendimento; articular-se com as famílias e a comunidade, criando processos de integração da sociedade com a escola; informar os pais e responsáveis sobre a frequência e o rendimento dos alunos, bem como sobre a execução de sua proposta pedagógica"( LDB, Art. 12, Incisos I a VII).
}

Desta feita, as práticas de gestão ("modelos praticados") seguem-se a partir de "modelos de gestão escolar", estes, modelos teóricos, como corpos de grandes princí- 
pios, de orientações genéricas e de perspectivas em torno da administração do sistema escolar e da organização e gestão das escolas (LIMA, 1996). "Enquanto modelos teóricos eles assumem um carácter geral e potencial, não necessariamente dependentes da ação e das práticas organizacionais efetivamente realizadas e abrindo, de resto, um leque mais ou menos vasto de opções concretas e congruentes em referência às perspectivas e orientações que encerram" (LIMA, 1996).

Existem vários tipos de modelos teóricos de referência, aqui se podendo incluir quer os modelos de análise das organizações escolares (corpos teóricos e conceptuais que nos permitem realizar leituras e ensaios descritivos e interpretativos das realidades escolares), quer os modelos normativistas que propõem princípios organizacionais e prescrevem soluções (isto é, que nos dizem como devemos administrar e organizar) com base em filosofias e em valores frequentemente desdobrados em métodos e em técnicas de administração e gestão, em instrumentos que operacionalizam as orientações programáticas de que partem.

Sendo esta uma área incomum entre os professores de Educação Física, é necessário que estes compreendam que a gestão escolar é um conjunto de atos que buscam integrar e promover melhorias em todas as condições materiais e humanas, garantindo avanços sócios educacionais e a uma melhor aprendizagem pelos alunos, além de estabelecer estratégias a fim de sustentar e dinamizar a existência multicultural (LÜCK, 2000). Complementarmente a gestão escolar pode ser definida como princípios capazes de integrar escola, educação, família e sociedade através da participação de todos (SAVIAVI, 1997). Assim, o envolvimento de todos os que fazem parte direta ou indiretamente do processo educacional, inclusive o professor de Educação Física, é imprescindível para o sucesso da gestão escolar participativa. De acordo com Amorim (2013) a Educação Física escolar tem muito a contribuir com o processo de gestão escolar, e para que esta contribuição se efetive deve-se procurar elaborar um bom planejamento, baseado na gestão pública, esportiva e escolar. Ações estas que podem influenciar de forma direta o estabelecimento de objetivos, solução de problemas, tomada de decisões, proposição, monitoramento e avaliação de planos de ação, visando os melhores resultados do processo educacional (LUCK, FREITAS, GIRLING e KEITH, 2007). Neste sentido, o presente estudo justifica-se pela abordagem de um 'novo' (incomum) campo de trabalho para o professor de Educação Física. Sendo assim, o objetivo do estudo é descrever a importância da gestão escolar para o professor de Educação Física e o comportamento deste como gestor escolar.

\section{PROCEDIMENTOS METODOLÓGICOS}

\section{Caracterização da Pesquisa}

Trata-se de um estudo com método descritivo, abordagem qualitativa e técnica narrativa (GAYA, 2016). 
ca dos dois sexos, com idades entre 25 e 57 anos, da cidade de Juiz de Fora, Minas Gerais. Destes nove eram atuantes e sete não atuantes no contexto escolar, com graduação entre 1981 e 2009 . Todos os participantes

desta pesquisa preencheram o termo de consentimento livre e esclarecido e uma declaração autorizando a utilização de todas as informações obtidas no trabalho.

Para a seleção dos sujeitos da pesquisa foram enviadas mensagens, via redes-sociais, a todos os professores do município com o intuito de convidá-los a participar da pesquisa. Após a divulgação da mensagem os

professores interessados se voluntariaram a participar da pesquisa assinando o termo de consentimento livre e esclarecido e a declaração de autorização. Este método de seleção de sujeitos se caracteriza por amostra voluntária (GAYA, 2016).

\section{Instrumento e Procedimento para Coleta de Dados}

Para a coleta de informação foi utilizado entrevistas semiestruturadas online formadas por sete questões abertas.

Na apresentação dos resultados, as respostas foram descritas de maneira a preservar a identidade dos entrevistados, e tais respostas seguiram a ordem das perguntas feitas em cada bloco, objetivando a coerência das informações. Juntamente ao resultado da entrevista, foi feita a discussão das principais questões narradas, de forma que o texto fique mais dinâmico e conciso em relação à temática do trabalho.

Os professores receberam um e-mail contendo informações sobre o presente estudo, o termo de consentimento livre e esclarecido juntamente com a declaração de autorização e o questionário com as perguntas. Tais perguntas foram divididas apriori em três categorias: 1- Gestão Escolar ("O que você entende por gestão na escola?", "Você se considera um gestor?", e "Você se sente capaz de ser um gestor escolar?”); 2- Importância da Gestão para os professores de Educação Física ("Qual a importância da gestão para o professor de educação física dentro da escola?", "Você considera que os conteúdos abordados nas Instituições de Ensino Superior sobre gestão são relevantes para a atuação dentro da escola? Por quê?", e "O desconhecimento deste conteúdo pode influenciar no trabalho do professor de educação física dentro da escola? Como?"); 3- Competências para o Gestor ("Quais as principais competências para um gestor escolar?”).

A extração dos dados foi realizada em planilha eletrônica, na qual as informações foram agrupadas em três domínios: (i) Gestão Escolar; (ii) Importância da Gestão para o professor de Educação Física (iii) Principais Competências. As categorias foram analisadas separadamente.

\section{RESULTADOS E DISCUSSÃO}

\section{Gestão Escolar}

Quando perguntados sobre o que entendem como gestão na escola, todos os 16 professores entrevistados tiveram conceitos bem semelhantes uns aos outros, podendo destacar a opinião de dois destes, conforme descrito abaixo: 
"É toda organização que circula internamente para gerenciar os recursos externos. Ou seja, os diretores, supervisores, secretários, professores, e demais funcionários, interagindo em grupo convergindo ao plano pedagógico da escola em questão" (Professor 5);

"[...] que uma direção/gestão precisa adotar uma postura democrática e participativa que contemple aspectos pedagógicos, administrativos, disciplinares e faça a integração dos mesmos com toda a comunidade escolar" (Professor 8).

Podemos perceber na fala dos professores que apesar de se evidenciar trechos que vão ao encontro do conceito de gestão escolar e suas incumbências, este conceito ainda não esta segmentado de forma clara e específica. O Professor 5 nos trás: "organização que circula internamente para gerenciar os recursos externos" (...) convergindo ao plano pedagógico da escola (...). De acordo com a LDB de 1996, a gestão escolar vai desde a elaboração e execução de sua proposta pedagógica como também a de administrar seu pessoal e seus recursos materiais e financeiros. O Professor 8 nos trás outro ponto da gestão escolar que converge a LDB de 1996, a articulação entre família e a comunidade, criando processos de integração da sociedade com a escola.

Indo de encontro com as respostas dos professores entrevistados, ser gestor é se tornar responsável por gerir os recursos disponíveis, podendo ser financeiros, humanos, administrativos e/ ou mesmo uma junção de todos. Deve estar sempre preparado para gerenciar, conduzir, determinar, articular e representar o ambiente o qual está inserido, tendo como função garantir a funcionalidade e continuidade das tarefas e da organização, bem como atender às expectativas de todos envolvidos.

Ainda referente a esta categoria, os entrevistados foram questionados quanto ao fato de se considerarem gestores.

Destes, três professores não se consideram gestores, dois professores se consideram gestores (porém, não gestores escolares) e 11 se consideram gestores. Desta forma destacam-se respectivamente alguns dos relatos, conforme descrito abaixo:

\footnotetext{
"[...] não me considero um gestor, pois não tive uma formação específica para tal cargo" (Professor 1);

"Acredito que tenho capacidade para gerir, mas não me considero um gestor no meio escolar, pois acredito que esta função na escola está muito mais relacionada ao diretor e supervisor do que aos professores, que têm funções muito mais de ensinar do que de gerir e coordenar" (Professor 8);

"Considero-me um gestor, pois sou capaz de atuar de forma interventiva no meu trabalho, realizando atividades as quais coordeno e executo de forma planejada e estruturada, além disso, elaboro planos de aula e planos de unidade" (Professor 3 ).
}

As falas supracitadas nos remetem a uma reflexão histórica no campo da Educação Física. Pimenta \& Lima (2006) evidenciam que em sua maioria, os currículos dos cursos de formação docente se constituem um aglomerado de disciplinas que não se articulam e também não explicitam a realidade escolar. Ponto importante a se considerar é que a partir da Resolução CFE n 03/87 (BRASIL, 1987), a formação em Educação Física foi preconizada em Bacharéis e Licenciados, organizando a estrutura da graduação de acordo com sua 
habilitação. A determinação das Diretrizes Curriculares Nacionais em 2002 (BRASIL, 2002) para a formação de educadores no geral, também afetou diretamente a área da Educação Física. As recomendações de elaboração de uma matriz curricular, sem exigências de um currículo mínimo, impactaram no aparecimento de cursos criados sem um eixo condutor. Pimenta \& Lima (2006) nos trazem que é possível avaliar que vários cursos de Licenciatura se pautam nos pontos fortes que as instituições têm a oferecer e não atendem a demanda necessária da profissão. Tendo em vista a grande diversidade de currículos nas diferentes IES de todo Brasil, os comentários dos professores devem ter um olhar cuidadoso, pois a realidade de cada um deles vai de encontros a sua IES de formação e também ao contexto histórico do mesmo.

$\mathrm{Na}$ terceira pergunta do bloco Gestão Escolar, os professores entrevistados foram questionados se sentem capazes de serem gestores escolares e a resposta foi surpreendente, uma vez que dos 16 entrevistados, 14 não se sentem capazes de serem gestores escolares, enquanto apenas dois sentem-se capazes.

\footnotetext{
"Não me sinto preparada para gerir uma escola, pois entendo que há diversos temas que não me foram passados na graduação. Não entendo de leis e não sei como aplicar o pouco do conhecimento recebido na universidade para gerir uma escola, acreditando ser necessária uma maior especialização na área, como cursos, palestras e uma vivência prática maior" (Professor 5); "[...] ser um gestor escolar é muito diferente de ser professor" (Professor 1); "Adquiri bastante experiência em todo tempo de atuação na área de licenciatura, e me vejo com capacidade de ser um gestor escolar. Na verdade, acredito que todos nós, graduados professores, temos capacidade de gerir e com isso sermos gestores, precisando apenas de boa vontade e aprofundamento" (Professor 13).
}

Nesta terceira questão fica ainda mais evidente que a maioria dos professores de Educação Física possui um conceito enviesado sobre a gestão escolar, que se confunde ao conceito da administração escolar, pois conforme o Menezes e Santos (2002) a expressão administração escolar é a utilização racional de fins educativos, enquanto que gestão escolar tem uma visão mais ampla, abrangendo todo o desenvolvimento da escola, sendo esta muito mais abrangente que a administração. Podemos citar como modelos de gestão escolar os modelos de análise das organizações escolares em que estaremos perante focalizações teóricas da escola como organização (Burocrática, ou como Arena Política, ou como Cultura, e outras), e também modelos normativistas posto que sejam confrontados com teorias organizacionais, escolas de pensamento, doutrinas gestionários ou sistemas de administração que focalizam normativamente a escola (do ponto de vista da Teoria da Contingência, do Desenvolvimento Organizacional, da Gestão por Objetivos ou do Planeamento Estratégico, entre outros) (LIMA 1996).

Contudo, o trabalho de gestão escolar exige, pois, o exercício de múltiplas competências específicas, tornando-se um desafio para os gestores. Fleury (2002) destaca que a multiplicidade de competências e a dinâmica constante das situações impõem novos desdobramentos e novos desafios ao gestor, sendo fundamental para a formação de gestores, um processo de formação continuada, em serviço, além de programas especiais e concentrada sobre temas específicos. 
Importância da Gestão para o professor de Educação Física:

Nesta categoria foram realizadas três perguntas aos entrevistados. A primeira delas foi sobre qual a importância da gestão para os professores de Educação Física, e tais respostas foram bem semelhantes:

\begin{abstract}
"Dentro da gestão do professor de educação física na escola entendo que ele deve ter conhecimento e habilidades para fazer interlocução entre sua ação pedagógica e o grupo gestor da mesma no que se refere às necessidades para o desenvolvimento de suas ações, na administração de conflitos, no conhecimento do corpo discente sob sua responsabilidade e inclusive de suas famílias para ter completo domínio na sua atuação" (Professor 3);

"A gestão é importante para que o professor compreenda o sistema organizacional que permeia a escola. O professor que conhece as estratégias gerenciais também é capaz de transitar entre as burocracias que envolvem as rotinas escolares com menor estresse e maior aproveitamento" (Professor 9).
\end{abstract}

Tendo como base as entrevistas, a gestão é uma área que se tornou de grande importância para a condução da escola, pois através de seus conhecimentos toda a equipe gestora, formada por diferentes setores da escola, estarão alinhados e trabalhando pelos mesmos objetivos e metas, facilitando a organização escolar e o trabalho pedagógico.

Posteriormente foram perguntados sobre a correlação entre os conteúdos de gestão abordados nas Instituições de Ensino Superior e a relevância na educação escolar. Neste quesito cinco dos entrevistados não acham relevantes os conteúdos de gestão abordados nas instituições devido ao fato de estes darem mais ênfase às práticas esportivas; três dos entrevistados consideram relevantes os conteúdos, porém acreditam que as instituições não conseguem direcionamento à disciplina; oito dos entrevistados acham relevantes. Tais posicionamentos são descritos abaixo respectivamente:

\footnotetext{
"Não considero importante para o âmbito escolar os conteúdos abordados na disciplina de gestão, uma vez que estes dão ênfase à gestão esportiva, na qual eu considero muito distinta da gestão escolar. Além disso, existem muitos outros conteúdos que são muito mais próximos da realidade de um colégio e que não são abordados" (Professor 5);

"A disciplina é interessante e acredito que se fosse dada de uma forma mais específica pelas universidades estas teriam um maior aproveitamento por parte dos alunos" (Professor 13); "É importante e esta inserido como parte funcional de um todo, o plano pedagógico da escola, de forma a gerenciar suas aulas de acordo com a realidade onde está inserido e o propósi to final que a escola busca" (Professor 3 ).
}

Através desta pergunta foi possível perceber que ainda há uma grande dificuldade por parte das Instituições de Ensino Superior em conseguir engajar a disciplina de gestão no currículo acadêmico. Por muitas vezes, como citado na entrevista por parte dos professores, tais Instituições utilizam a disciplina com ênfase apenas na gestão esportiva, deixando de lado ambientes o qual a gestão pode ser empregada.

Finalizando, foram questionados quanto ao desconhecimento da disciplina e a influência nas aulas de educação Física na escola. Em relação a está pergunta dois dos professores entrevistados não acreditam que haja relação entre à situação, enquanto 14 acreditam na relação entre os temas: 


\begin{abstract}
"O trabalho do professor de educação física na escola é dar aulas de Educação Física. A gestão pode auxiliá-lo no processo organizacional de seu trabalho e suas relações. No que tange ao conteúdo e ao aluno não há influência" (Professor 1);

"Acredito que sim, principalmente para profissionais recém-formados sem nenhum conhecimento prático em sua área de atuação. Além disso, considero como parte do planejamento, elaboração e construção dos planos de aula e planos de unidade" (Professorg).
\end{abstract}

Todos os profissionais, independentemente de sua área de atuação necessitam de conhecimentos de gestão, no espaço escolar não seria diferente. O gestor deve estar apto a assumir posturas profissionais referentes ao contexto da prática escolar, além de influências públicas e pedagógicas. Os conhecimentos de gestão para o professor de educação física é importante para que este além de ter competência para realizar, organizar e promover eventos esportivos escolares (AMORIM, 2013) seja também capaz de coordenar equipes de trabalho, com domínio do conhecimento, habilidades e domínio das atitudes.

Indo de encontro com a maioria dos entrevistados, Rezende (2000) comenta que o professor de educação física além de desempenhar as funções de ensinar e educar durante suas aulas, deve ter consciência que é capaz de assumir funções administrativas, em cargos de supervisão, gerência, diretoria ou mesmo de proprietário/administrador.

Porém, o que também se observa é um déficit em relação às exigências do novo mercado de trabalho e os conteúdos abordados dentro das disciplinas de gestão esportiva e gestão escolar nas Instituições de Ensino Superior. Por se tratar de um curso com uma gama enorme de conteúdos, por muitas vezes há uma saturação de carga horária em algumas disciplinas e um enxugamento em outras, gerando uma má distribuição destes. Diante disso, Amorim (2013) afirma que apenas a graduação por si só não é suficiente, uma vez que a gestão é muito mais abrangente e deveria ser mais abordada (PIRES e SARMENTO, 2001).

Desta forma, os professores de educação física revelam através da entrevista dificuldades de relacionarem os temas de gestão e gestão escolar, tendo estes por muitas vezes a ideia equivocada de que ser professor é algo totalmente à parte do processo de gerir, fazendo que estes não se sintam aptos a coordenar o ambiente escolar. É importante destacar a necessidade de mais investimentos educacionais nas Instituições de Ensino Superior no que tange às disciplinas de gestão (esportiva e escolar), elaborando currículos de forma a abranger tais necessidades e melhor preparar os acadêmicos para as práticas efetivas da área, uma vez que embasada neste estudo encontramos dificuldades de os professores de educação física se relacionar com tais conteúdos de forma prática no âmbito escolar.

Principais Competências:

Quando perguntados sobre quais as principais competências para um gestor escolar, todos os 16 professores entrevistados possuem uma ideia muito semelhante, cuja quais podemos destacar:

"Entendo ser necessário ao gestor ter uma visão abrangente de toda a escola e do trabalho que ali se desenvolve. Assim, criar um ambiente motivador da aprendizagem e de agradável convivência, aplicar recursos físicos de acordo com as necessidades da escola, articular os segmentos e monitorar/avaliar resultados, configuram o que entendo como indispensável á gestão 
eficiente" (Professor 10).

"Planejar, executar, assessorar com responsabilidade a instituição escolar" (Professor 7).

"Planejar, avaliar e re-planejar" (Professor 1).

Já é amplamente reconhecido que uma educação de qualidade está intimamente relacionada à competência dos profissionais envolvidos, sendo estes capazes de oferecer conhecimentos, habilidades e atitudes necessárias para que os alunos possam integrar a sociedade de forma mais eficiente (LÜCK, 2000).

Ser gestor nos dias de hoje é uma tarefa que exige dedicação e diversas competências, que fazem com que haja uma maior busca por conhecimento. É de extrema importância que os gestores sejam capazes de visualizar, analisar, planejar e executar com qualidade e competência seja em qual for o ambiente.

Baseado nas entrevistas dos professores de educação física foi possível observar que há uma equivalência nas respostas quanto às principais competências para um gestor, e que planejamento é uma importante ação dentro deste nicho. Incluo ainda que saber agir e saber executar são elos fundamentais para que o planejamento seja concluído com êxito.

\section{CONSIDERAÇÕES FINAIS}

A partir desta investigação cujo objetivo era analisar a importância da gestão para o professor de Educação Física e o comportamento deste como gestor, pôde ser percebido, entre os professores entrevistados, que esta é de enorme importância para a atuação no ambiente escolar, porém, ainda há um grande desconhecimento por parte dos professores de Educação Física em como integrar e se relacionar com algumas questões administrativas para tais realizações. Apesar de se considerarem gestores, por muitas vezes não se sentem capazes de ser um gestor escolar. Através disso, as Instituições de Ensino Superior deveriam ser uma importante instituição capaz de sanar tais dificuldades, aliando conteúdos práticos e teóricos a fim de elaborar currículos mais atualizados e que abordem melhor a área de gestão escolar. Além disso, ainda são poucos os estudos que relacionem o professor como gestor, principalmente o Educador Físico, o que deixa inúmeros questionamentos a serem investigados em estudos futuros.

\section{REFERÊNCIAS}

AMORIM, F. W. P. A importância da gestão esportiva para a vida do professor de educação física. Porto Alegre, 2013.

ANVESSA, A. L. B.; OLIVEIRA, A. A. B. Competências profissionais demandadas pelo mercado de trabaIho. Revista Pensar a Prática, Goiânia, 14 (3), 2011.

AZEVEDO, P.H.; BARROS, J. F. A necessidade de administração profissional do esporte brasileiro e o perfil do gestor público, em nível federal, que atuou de 1995 a 2002. Revista Digital, Buenos Aires, 10 (74), 2004. 
BASTOS, F. C. Perfil de gestores de redes de academias de Fitness. Revista Mineira de Educação Física, Viçosa, 19 (1), 64-74, 2011.

BASTOS, F. C.; MAZZEI, L. C. Gestão do esporte no Brasil desafios e perspectivas. São Paulo: Ícone. 2012.

BASTOS, F.C. Sport manager's fields of practice: propose of a model for Brazil. The FIEP Bulletin, Foz do Iguaçu, v.74, p.429-31, 2004.

BRASIL, Ministério de Educação e do Desporto. Parâmetros Curriculares Nacionais: terceiro e quarto ciclos: Educação Física / Secretaria de Ensino Fundamental. Brasília: MEC/SEF, 1998a.

BRASIL. Conselho Federal de Educação. Resolução n. 03, de 16 de junho de 1987. Fixa os mínimos de conteúdo e duração a serem observados nos cursos de graduação em Educação Física (Bacharelado e/ ou Licenciatura Plena). Diário Oficial da União, Brasília, DF, 10 set. 1987.

BRASIL. Ministério da Educação. Resolução CNE/CP 1, de 18 de fevereiro de 2002 e Resolução CNE/CP 2, de 19 de fevereiro de 2002. Diretrizes Curriculares Nacionais para a Formação de Professores da Educação Básica em nível superior, curso de licenciatura, de graduação plena. Brasília: MEC, 2002.

CONFEF. Conselho Federal de Educação Física - Resolução 156/2008. Disponível em: <HTTP://www.confef.org.br/extra/conteudo/defaut.asp?id=471> acesso em:16/10/2014.

FERRÃO, M. E. et al. O Saeb - Sistema Nacional de Avaliação da Educação Básica: objetivos, características e contribuições na investigação da escola eficaz. Revista Brasileira de Estudos de População. V.18, n.1/2, jan./dez, 2001.

FLEURY, M. T. A gestão de competência e estratégia organizacional. As pessoas na organização. São Paulo: Gente, 2002.

GAYA, A. Projetos de pesquisas científicas e pedagógicas. O desafio da iniciação científica. Belo Horizonte: Casa da Educação Física, 2016.

GAYA, Adroaldo. Ciências do movimento humano: introdução à metodologia da pesquisa. Artmed, 2008.

GONÇALVES, J. S. L. As empresas são grandes coleções de processos. RAE - Revista de Administração de Empresas, São Paulo, 40 (1), 2000.

ILHA, F. R. S.; KRUG, H. N. O professor de Educação física e sua participação na gestão escolar: contribuição para a formação profissional. Revista e-Curriculum, PUCSP - SP, Volume 4, numero 1, dez. 2008.

KRAWCZYK, Nora. A gestão escolar: um campo minado... Análise das propostas de 11 municípios brasileiros. Educação \& Sociedade, 1999.

LIBÂNEO, J. C. et al. Educação Escolar: políticas, estrutura e organização. 7. ed. São Paulo: Cortez, 2009. 
LIMA, L. C. Construindo modelos de gestão escolar. Instituto de Inovação Educacional, 1996.

LÜCK, H. Dimensões da Gestão Escolar e suas Competências. Positivo. Curitiba, 2009.

LÜCK, H. Gestão educacional: uma questão paradigmática. 2. ed. Petrópolis: Vozes, 2007.

LÜCK, H. Liderança em gestão escolar. Petrópolis: Vozes, 2008.

LÜCK, H. Perspectivas da Gestão Escolar e implicações quanto à formação de seus gestores. Em aberto, Brasília, v.17, n.72, 11-33, fev. / jun.2000.

LUCK, H.; FREITAS, K. S.; GIRLING, R.; KEITH, S. A escola participativa: o trabalho do gestor escolar, $4^{\mathrm{a}}$ edição, Petrópolis, RJ: Vozes, 2007.

MENEZES, E. T.; SANTOS, T. H.”Gestão escolar" (verbete). Dicionário Interativo da Educação Brasileira - EducaBrasil. São Paulo: Midiamix Editora, 2002.

NASCIMENTO, P. R. B; ALMEIDA, L. A tematização das lutas na Educação Física Escolar: restrições e possibilidades. Revista Movimento, v. 1, n. 3. p. 91-110, set./dez. 2007.

PARKHOUSE, Bonnie L. The Manangement of Sports: Its Foundation and Application. St. Louis: Mosby Year Book, 1996.

PIMENTA, S. G.; LIMA, M. S. L. Estágio e docência: diferentes concepções. Poíesis Pedagógica, v. 3, n. 3 e 4, p. 5-24, 2006.

REZENDE, J. R. Organização e administração do esporte. Rio de Janeiro, Sprint, 2000.

RIBEIRO, S. R. Perspectivas de atuação do profissional de Educação física: perfil de habilidades no atual contexto de mercado e formação inicial. XII Encontro Latino Americano de Iniciação Científica e VIII Encontro Latino Americano de Pós-Graduação - Universidade do Vale do Paraíba, 2008.

SARMENTO, J. P.; PIRES, G. M. Conceito de Gestão do Desporto. Novos desafios, diferentes soluções. Revista Portuguesa de Ciências do Desporto, 1(1), 88-103, 2001.

SOARES, C. L. Educação Física Escolar: Conhecimento e Especificidade. Revista Paulista de Educação Física. São Paulo, supl. 2, p. 6-12, 1998.

TRIVIÑOS, A. N. S. Introdução à pesquisa em ciências sociais: a pesquisa qualitativa em Educação. São Paulo: Atlas, 1987.

VERLI, M. S.; BRAUNER, V. L. P. Os conteúdos da educação física na escola: da seleção à aplicação. Revista da Graduação / Rio Grande do Sul - PUCRS, v. 4, n.1, 2011.

VIEIRA, S. L. ALBUQUERQUE, M. G. M. Política e planejamento educacional. 3.ed. revista e modificada. Fortaleza: Edições Demócrito Rocha, 2002.

WARDE, M. Jorge. "Considerações sobre a autonomia da escola”. Revista Idéias: O diretor-articulador do projeto de escola. São Paulo: FDE, 1992. 